\title{
Video Article \\ Parallel-plate Flow Chamber and Continuous Flow Circuit to Evaluate Endothelial Progenitor Cells under Laminar Flow Shear Stress
}

\author{
Whitney O. Lane ${ }^{1}$, Alexandra E. Jantzen ${ }^{2}$, Tim A. Carlon ${ }^{2}$, Ryan M. Jamiolkowski ${ }^{3}$, Justin E. Grenet ${ }^{1}$, Melissa M. Ley ${ }^{1}$, Justin M. Haseltine ${ }^{2}$, Lauren \\ J. Galinat ${ }^{2}$, Fu-Hsiung Lin ${ }^{1}$, Jason D. Allen ${ }^{4}$, George A. Truskey ${ }^{2}$, Hardean E. Achneck ${ }^{1}$ \\ ${ }^{1}$ Department of Surgery, Duke University Medical Center \\ ${ }^{2}$ Department of Biomedical Engineering, Duke University \\ ${ }^{3}$ School of Medicine, University of Pennsylvania \\ ${ }^{4}$ Department of Medicine, Division of Cardiology, Duke University Medical Center
}

Correspondence to: Hardean E. Achneck at hardean.achneck@duke.edu

URL: https://www.jove.com/video/3349

DOI: doi:10.3791/3349

Keywords: Bioengineering, Issue 59, Fluid Shear Stress, Shear Stress, Shear Force, Endothelium, Endothelial Progenitor Cells, Flow Chamber, Laminar Flow, Flow Circuit, Continuous Flow, Cell Adhesion

Date Published: 1/17/2012

Citation: Lane, W.O., Jantzen, A.E., Carlon, T.A., Jamiolkowski, R.M., Grenet, J.E., Ley, M.M., Haseltine, J.M., Galinat, L.J., Lin, F.H., Allen, J.D., Truskey, G.A., Achneck, H.E. Parallel-plate Flow Chamber and Continuous Flow Circuit to Evaluate Endothelial Progenitor Cells under Laminar Flow Shear Stress. J. Vis. Exp. (59), e3349, doi:10.3791/3349 (2012).

\section{Abstract}

The overall goal of this method is to describe a technique to subject adherent cells to laminar flow conditions and evaluate their response to well quantifiable fluid shear stresses ${ }^{1}$.

Our flow chamber design and flow circuit (Fig. 1) contains a transparent viewing region that enables testing of cell adhesion and imaging of cell morphology immediately before flow (Fig. 11A, B), at various time points during flow (Fig. 11C), and after flow (Fig. 11D). These experiments are illustrated with human umbilical cord blood-derived endothelial progenitor cells (EPCs) and porcine EPCs ${ }^{2,3}$.

This method is also applicable to other adherent cell types, e.g. smooth muscle cells (SMCs) or fibroblasts.

The chamber and all parts of the circuit are easily sterilized with steam autoclaving. In contrast to other chambers, e.g. microfluidic chambers, large numbers of cells ( $>1$ million depending on cell size) can be recovered after the flow experiment under sterile conditions for cell culture or other experiments, e.g. DNA or RNA extraction, or immunohistochemistry (Fig. 11E), or scanning electron microscopy ${ }^{5}$. The shear stress can be adjusted by varying the flow rate of the perfusate, the fluid viscosity, or the channel height and width. The latter can reduce fluid volume or cell needs while ensuring that one-dimensional flow is maintained. It is not necessary to measure chamber height between experiments, since the chamber height does not depend on the use of gaskets, which greatly increases the ease of multiple experiments. Furthermore, the circuit design easily enables the collection of perfusate samples for analysis and/or quantification of metabolites secreted by cells under fluid shear stress exposure, e.g. nitric oxide (Fig. 12).

\section{Video Link}

The video component of this article can be found at https://www.jove.com/video/3349/

\section{Endothelial progenitor cell isolation}

1. Prior to any collection of peripheral human blood, submit your research protocol to your Institutional Review Board (IRB), and after its approval, obtain the volunteer donors' informed consent (peripheral blood collection and EPC isolation had been approved by the Duke University IRB and is in full compliance with U.S. regulatory requirements related to the protection of human research participants).

2. When working with animal-derived EPCs, have your research protocol approved by your Institutional Animal Care and Use Committee (IACUC). All our porcine experiments had been approved by the Duke University IACUC and were conducted in accordance with the highest standards of humane care.

3. For isolation of endothelial progenitor cells, collect $50 \mathrm{ml}$ of peripheral blood via standard phlebotomy technique from a consented volunteer donor into blood collection bags filled with the anticoagulant citrate phosphate dextrose and dilute the solution 1:1 with Hank's buffered salt solution (without $\mathrm{CaCl}_{2}, \mathrm{MgCl}_{2}, \mathrm{MgSO}_{4}$ ) and layer on equal volumes of Histopaque to create well-defined layers.

4. Centrifuge (30 min, $740 \mathrm{~g}$, low break setting) and collect the mononuclear cell (MNC) (buffy coat) layer. Resuspend and wash MNCs $\times 3$ with Dulbecco's Phosphate Buffered Saline (DPBS) with 10\% Fetal Bovine Serum (FBS) $\times 10$ min, $515 \mathrm{~g}$, before plating into two 12-well plates in full EPC growth medium (MCDB-131 medium with $5 \mathrm{ml}$ of $200 \mathrm{mM} \mathrm{L}$-glutamine, $10 \% \mathrm{FBS}$ and EGM-2 SingleQuots) at $37{ }^{\circ} \mathrm{C}, 5 \% \mathrm{CO}_{2}$. 
5. Slowly change medium every 24 hours for the first 7 days, then every other day. EPC colonies can be identified after an average time of 14 days based on their cobblestone morphology. Once EPCs in culture cover $1 / 4$ of the 12 -well surface area, expand cells and confirm EPC identity with flow cytometry by testing for presence of surface markers CD31 and absence of CD14, CD45 as previously described ${ }^{6}$. Other assays that may be performed include cell morphology and labeling with Dil-Ac-LDL.

6. For the experiments described herein, expand isolated EPCs until they are nearly confluent in $3 \mathrm{~T}-75$ cell culture flasks in EPC medium in a humidified incubator at $37^{\circ} \mathrm{C}, 5 \% \mathrm{CO}_{2}$.

\section{Shear stress calculation}

1. We recommend that these calculations are performed before manufacturing the chamber and channel to have a thorough understanding of the conditions that can be achieved. Calculate the flow rate of the perfusate in your circuit based on the desired shear stresses to be applied to the cells according to equation $1^{1}$,

$$
Q=\frac{\tau \cdot w \cdot h^{2}}{6 \cdot \mu}
$$

where $\boldsymbol{Q}$ is the desired flow rate, $\boldsymbol{\tau}$ is the target shear stress acting tangentially on the cells, $\boldsymbol{w}$ is the width of the flow chamber, $\boldsymbol{h}$ is the height of the flow chamber, and $\boldsymbol{\mu}$ is the viscosity of the perfusate (flow medium).

2. A typical value of viscosity $(\mu)$ for medium used is $0.9 \mathrm{cP}\left(0.009 \mathrm{~g} \mathrm{~cm}^{-1} \mathrm{~s}^{-1}\right)$. Note that the viscosity can also be raised by using high molecular

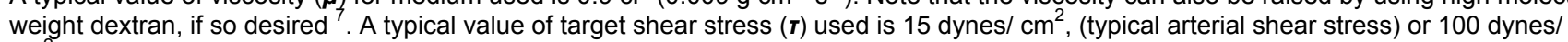
$\mathrm{cm}^{2}$, if supra-physiological shear stress is desired. Our chamber typically has a width (w) of $1.9 \mathrm{~cm}$ and height $(\boldsymbol{h})$ in the range of $166-267$ $\mu \mathrm{m}$.

\section{Flow chamber manufacturing}

1. Cut the top and bottom plates of the chamber from aluminum alloy 6061 rectangular stock with top dimension of $7 \times 2 \times 0.5$ " and bottom dimensions of $7 \times 2 \times 0.25 "$.

2. Recess the top plate in the center portion to 0.125 " deep, leaving 0.950 " per end for 1.375 " wide $\times 0.3125$ " deep fluid reservoir.

3. Drill $1 / 16$ " wide $\times 0.625$ " long slots from the underside in order to penetrate to the reservoir on the inflow and outflow ends.

4. At the end of each top plate, drill a centrally located 10/32" tracks per inch (T.P.I.) hole for polypropylene 1/8" hose barb to penetrate the fluid reservoir. On the inflow end, create a side plug with 10/32" T.P.I through hole for polypropylene 1/8" hose barb.

5. Taper the top underside from the fluid inflow to the glass viewing window at 0.518 degrees for adequate mixing of fluid.

6. Cut a glass slide window into the bottom plate in line with the top viewing window. Using aquarium cement, glue a glass slide into the chamber. Allow to cure for at least 24 hours. Ensure that the viewing window is recessed so that a $75 \times 25 \times 1$ mm microscope glass slide will sit flush in the chamber.

7. Create a recess for an O-ring around the underside of the top and bottom plates such that they are spaced apart by $0.02 "$ ". Insert the rubber O-rings.

8. Drill 10 matching $8 / 32 "$ T.P.I. holes in top and bottom chambers for use with $8 / 32$ " flat head screws.

\section{Flow circuit assembly}

1. Assemble the entire flow circuit first, then proceed with its sterilization.

2. Attach a 36" segment of hard tubing to one end of the pulse dampener (via 1/8" connection). To the other end, attach an 18 " segment of soft tubing.

3. Place a $1 / 8$ " male luer adaptor at the end of the 18 " soft tubing section, mentioned in step 4.2 . Connect the male luer to a $1 / 8$ " female luer adaptor. Attach the female luer to a new 18" segment soft tubing.

4. Drill three holes into a $250 \mathrm{ml}$ glass beaker cap in order to fit tubing. Insert a 1.5" segment of soft tubing (as air vent) into one hole and the free ends of the hard and soft tubing through the other 2 holes in the cap into the $250 \mathrm{ml}$ glass bottle (as reservoir) (Fig. 2). Ensure that the hard tubing reaches the bottom of the reservoir (as outflow tubing from the reservoir).

5. Sterilize the above parts by steam autoclaving at $121^{\circ} \mathrm{C}$ for $60 \mathrm{~min}$. Additionally autoclave one complete flow chamber, $3 \times 2$ " segments of soft tubing, 1 male and 1 female 1/8" luer adaptor, $4 \times 1 / 2$ " and $6 \times 5 / 16$ " 8-32 flat head screws, 1 pair of tweezers, one $75 \times 25 \times 1 \mathrm{~mm}$ glass slide (or other desired cell surface material), and 2 surgical towels.

6. Place sterile towels into laminar flow hood. Place the flow circuit, flow chamber, $4 \times 4$-way stopcocks, $1 \times 1$-way stopcock, and all the sterilized parts from step 4.5 onto this sterile field.

7. Now use sterile gloves to connect two 4-way stopcocks. Place caps on the open sample ports.

8. Detach the male and female luer adaptors attaching the two soft tubing segments of the flow circuit and insert the connected stopcocks (Fig. 3).

9. Attach the soft tubing inserted into the reservoir to a $30 \mathrm{ml}$ syringe and remove the syringe piston. Fill the bottle with $125 \mathrm{ml}$ of EPC medium (Fig. 4).

10. Place a sterile syringe filter into the air vent (Fig. 4).

11. Move the flow circuit into a humidified incubator at $37^{\circ} \mathrm{C}, 5 \% \mathrm{CO}_{2}$.

12. Clamp the hard tubing into the roller pump head indicated for use with this type of tubing (Fig. 5). Ensure that the tubing does not overlap with the roller pump mounting tracks. Mark the tubing where it exits the pump head on either side with a marking pen.

13. Ensure that all stopcocks are closed off towards the sample ports and open along the flow circuit. Start the pump. Verify the direction of flow. The perfusate should move from the glass reservoir through the hard tubing into the pulse dampener. 


\section{EPC fluorescent labeling}

1. While the flow circuit warms to $37^{\circ} \mathrm{C}$, prepare the cells for seeding onto the slide. Note that fluorescent labeling is required if cells are to be visualized on opaque materials, e.g. titanium (Ti).

2. Create a $1 \mathrm{mM}$ stock solution of Cell Tracker Orange (CTO) by diluting $50 \mu \mathrm{g} \mathrm{CTO} \mathrm{powder} \mathrm{with} 90 \mu \mathrm{l}$ of dimethyl sulfoxide (DMSO). Be sure to shield this mixture from light exposure (turn off light while working under flow hood).

3. Create a $2 \mu \mathrm{M}$ working solution of CTO by diluting $36 \mu \mathrm{l}$ of CTO stock solution into $18 \mathrm{ml}$ of serum-free MCDB-131 medium.

4. Rinse EPCs in 3 near confluent T-75 cell culture flasks with $10 \mathrm{ml}$ DPBS (without $\mathrm{Ca}$ or $\mathrm{Mg}$ ).

5. Add $6 \mathrm{ml}$ of the $2 \mu \mathrm{M}$ CTO working solution to each flask. Incubate for $15 \mathrm{~min}$ at $37^{\circ} \mathrm{C}$. Rinse each flask $\times 2 \mathrm{with} 10 \mathrm{ml} \mathrm{DPBS}$ (without Ca or $\mathrm{Mg})$.

6. Add $4 \mathrm{ml}$ of Trypsin to each flask. Incubate at $37^{\circ} \mathrm{C}$ for $3 \mathrm{~min}$. Neutralize with $8 \mathrm{ml}$ of Trypsin Neutralization Solution.

7. Wash by centrifugation $\times 5 \mathrm{~min}$ at $600 \mathrm{~g}$ and resuspend in $5 \mathrm{ml}$ of EPC medium.

\section{Cell seeding of slide prior to flow chamber assembly}

1. A slide made out of glass, titanium, or other material can be used, and the slide surface can be modified by spin coating with polymer or adding a layer of metal. Place the slide into a sterile rectangular four-chamber cell culture vessel (or use tissue culture slide flask if polystyrene surface is desired). Count cells and seed $1.5 \times 10^{6}$ cells onto the slide in $5 \mathrm{ml}$ of EPC medium $\times 6 \mathrm{hr}$ if a confluent cell layer is desired at the initiation of flow (Fig. 11A).

2. In order to test cell spreading and adhesion under fluid shear stress, allow $3 \times 10^{6}$ cells to adhere for only 15 min before commencement of flow (quick-seeding) (Fig. 11B).

\section{Flow chamber assembly}

1. Using sterile gloves, connect one 2" soft tubing segment to a $1 / 8$ " female luer adaptor. Connect another 2 " soft tubing segment to a $1 / 8$ " male luer adaptor.

2. Attach the 2" soft tubing with female luer adaptor to the inflow port. Attach the 2" soft tubing with male luer to the outflow port. Attach 4-way stopcocks to both of these luer adaptors. Connect the remaining 2 " soft tubing piece to the side port connector coming off the bubble trap and attach a 1-way stopcock (Fig. 6).

3. Using sterile tweezers, remove the cell-seeded slide from the cell culture vessel (or if using a slide flask, remove the flask on slide) and place it into the recess on the bottom plate of the flow chamber. Make sure that the slide is placed with the cell-seeded side facing up.

4. Pipet $10 \mathrm{ml}$ of warm EPC medium onto the slide. Allow the medium to cover the slide and flow chamber, but do not spill the medium over the O-ring on the bottom plate.

5. Place the top plate of the flow chamber onto the bottom plate, aligning the screw holes. Take care not to introduce air bubbles into the chamber during this step by keeping the two plates parallel.

6. Screw plates together (an automatic battery-operated screwdriver speeds up this process).

7. Remove air bubbles from inflow bubble trap by opening the 1-way stopcock attached to the inflow-side bubble trap port and gently flush the inflow tubing with EPC medium using a $10 \mathrm{ml}$ syringe. Then close off this stopcock and cap it (Fig. 7).

8. Now remove air bubbles from the chamber channel by opening the outflow port 4-way stopcock and by gently flushing EPC medium through the flow chamber, again using a $10 \mathrm{ml}$ syringe. If large bubbles remain, raise the outflow end of the chamber to a $45^{\circ}$ angle (Fig. 8).

9. Cap all of the 4-way stopcock connections and close them off. Move the flow chamber into the incubator with the assembled flow circuit ( Fig. 9).

10. Pause the flow circuit pump. Close off the flow circuit stopcocks in the direction of flow to prevent leakage and to keep the inside of the chamber sterile. Transport the flow chamber from the flow hood to the flow circuit. Connect the flow chamber to the flow circuit. Open the stopcocks in the direction of flow. Resume the flow pump. Ensure that the perfusate flows in the correct direction. Adjust the flow rate to the desired shear stress.

11. During the flow experiment, the flow chamber can be removed from the circuit to image the cells via light or fluorescent microscopy. In order to do so, disconnect the flow chamber from the flow circuit at the stopcock-stopcock connections. To maintain sterility of the chamber, close off the flow circuit stopcocks and flow chamber stopcocks in the direction of flow and cap all stopcocks prior to removing the flow circuit from the incubator (Fig. 9).

\section{Perfusate sample collection}

1. For easy collection of perfusate samples for analysis, (e.g. nitric oxide synthesis), first pause the pump.

2. Close the stopcock located closest to the pulse dampener. Remove its protective cap and insert a small size syringe, e.g. $3 \mathrm{ml}$ syringe, into the sample port. Keep cap and ensure that it will not become contaminated by placing it upside down.

3. Close the stopcock in the direction of the flow chamber, keeping the sample port and circuit in the direction of the pulse dampener open.

4. Draw desired amount of sample, e.g. $150 \mu \mathrm{l}$, from the circuit. Close off the stopcock towards the sample port before removing the syringe. Store the perfusate sample in a labeled vial and freeze at $-80^{\circ} \mathrm{C}$ (for nitric oxide determination at a later time point).

5. Recap the sample port and ensure that all stopcocks are open before commencing flow.

\section{Representative results}

Using our quick-seed method, human blood-derived endothelial progenitor cells can be seeded onto titanium slides for 15 minutes and adhere under physiological (arterial) shear forces of 15 dynes $/ \mathrm{cm}^{2}$. 
As shown in Figure 10, EPCs spread under the influence of flow from $210 \pm 11.4 \mu \mathrm{m}^{2}$, immediately after seeding, to $657 \pm 39.1 \mu \mathrm{m}^{2}$ after 3 hours, and to $1152 \pm 55.3 \mu \mathrm{m}^{2}$ after 24 hours of fluid shear stress of $15 \mathrm{dynes} / \mathrm{cm}^{2}$ (difference between the groups is statistically significant with $p<0.0001,1$-way ANOVA). Parallel to the increase in cell area, which can be imaged through the transparent chamber with either light or fluorescent microscope, the roundness calculated according to equation $2^{6}$

$$
\text { Roundness }=\frac{4 \times \pi \times \text { Area }}{\text { Perimeter }}
$$

decreased from $878 \times 10^{-3} \pm 5.9 \times 10^{-3}$, immediately after seeding, to $671 \times 10^{-3} \pm 19.2 \times 10^{-3}$ after 3 hours, and to $526 \times 10^{-3} \pm 19.2 \times 10^{-3}$ after 48 hours of the same fluid shear stress exposure (difference between the groups is again statistically significant with $p<0.0001,1$-way ANOVA).

Figure 11D illustrates that EPCs align and orient in the direction of flow after 48 hours of fluid shear stress at $15 \mathrm{dynes} / \mathrm{cm}^{2}$ as compared to their random orientation after a static seeding period of 6 hours, shown in Figure 11A.

Our method also allows for obtaining samples of the perfusate at predetermined time points for the analysis and/or quantification of secreted cell metabolites. As a representative example we depict the production of nitrite $\left(\mathrm{NO}_{2}-\right)$ during a 48 hour flow experiment with porcine EPCs in Figure 12. We directly measured this primary oxidation product of nitric oxide (NO) as a surrogate marker for NO in medium samples collected from the flow circuit at the different time points to be $12.0 \mathrm{nmol}$ at 6 hours, $13.1 \mathrm{nmol}$ at 12 hours, $16.3 \mathrm{nmol}$ at 24 hours, and $24.6 \mathrm{nmol}$ after 48 hours for $1 \times 10^{6}$ cells at 15 dynes $/ \mathrm{cm}^{26}$.

A)

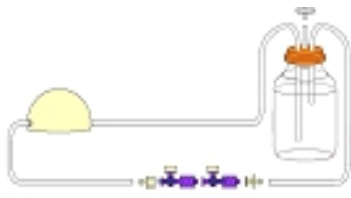

B)

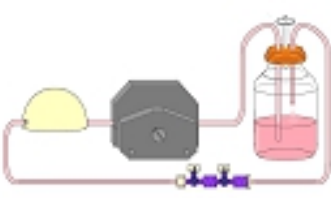

C)
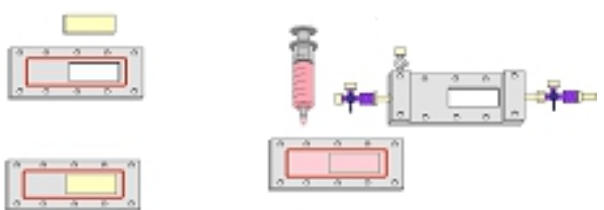

\section{D)}

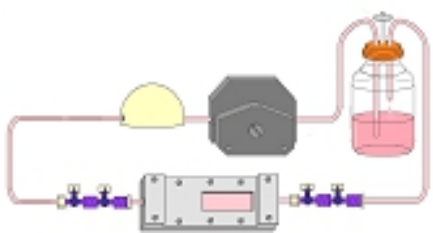

Figure 1. Schematic showing an overview of the flow circuit assembly and flow experiment. (A) Flow circuit assembly without the flow chamber. Included here are the reservoir, pulse dampener, hard tubing, soft tubing, 4-way stopcocks and connected luer adaptors, as well as air filter. (B) Connecting the flow chamber via the hard tubing segment to the flow pump head. (C) Insertion of the EPC-seeded slide into the bottom plate of the flow chamber (D). Complete assembly of the flow circuit with the flow chamber. 


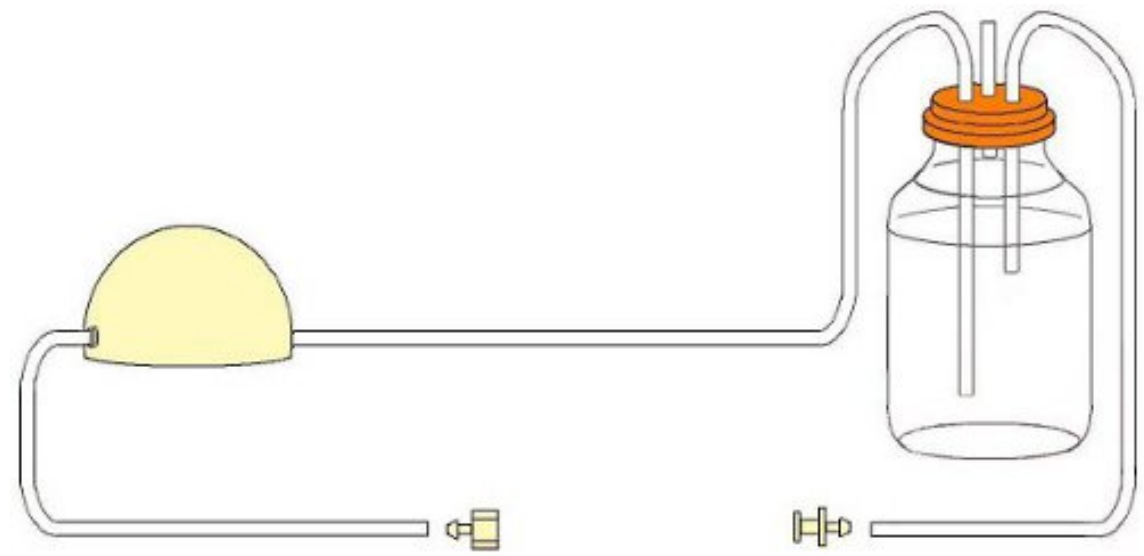

Figure 2. Completely assembled flow circuit for sterilization.

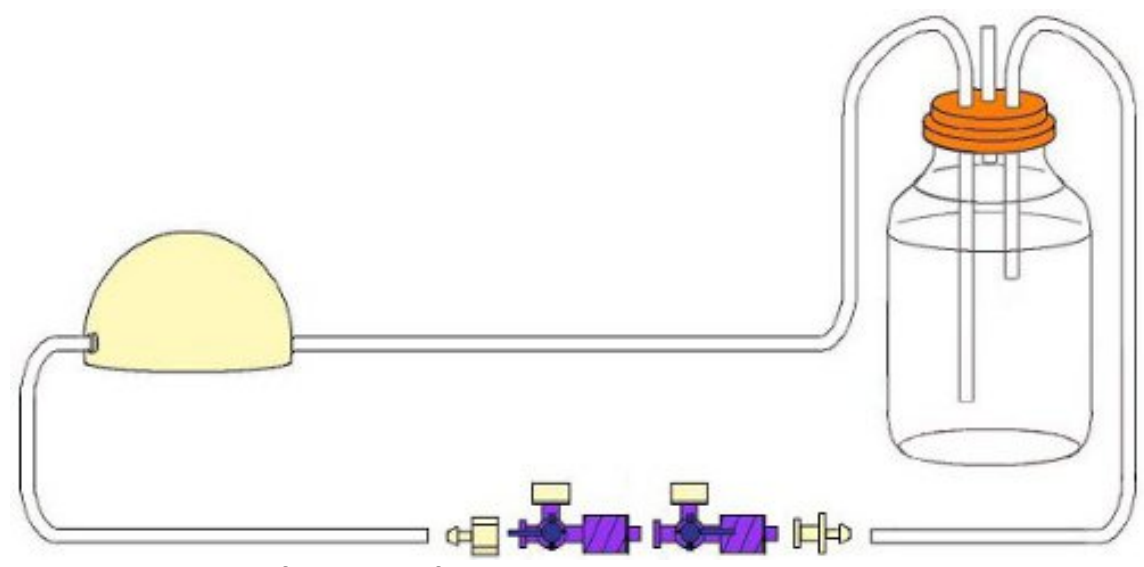

Figure 3. Assembled flow circuit after sterilization with stopcocks included.

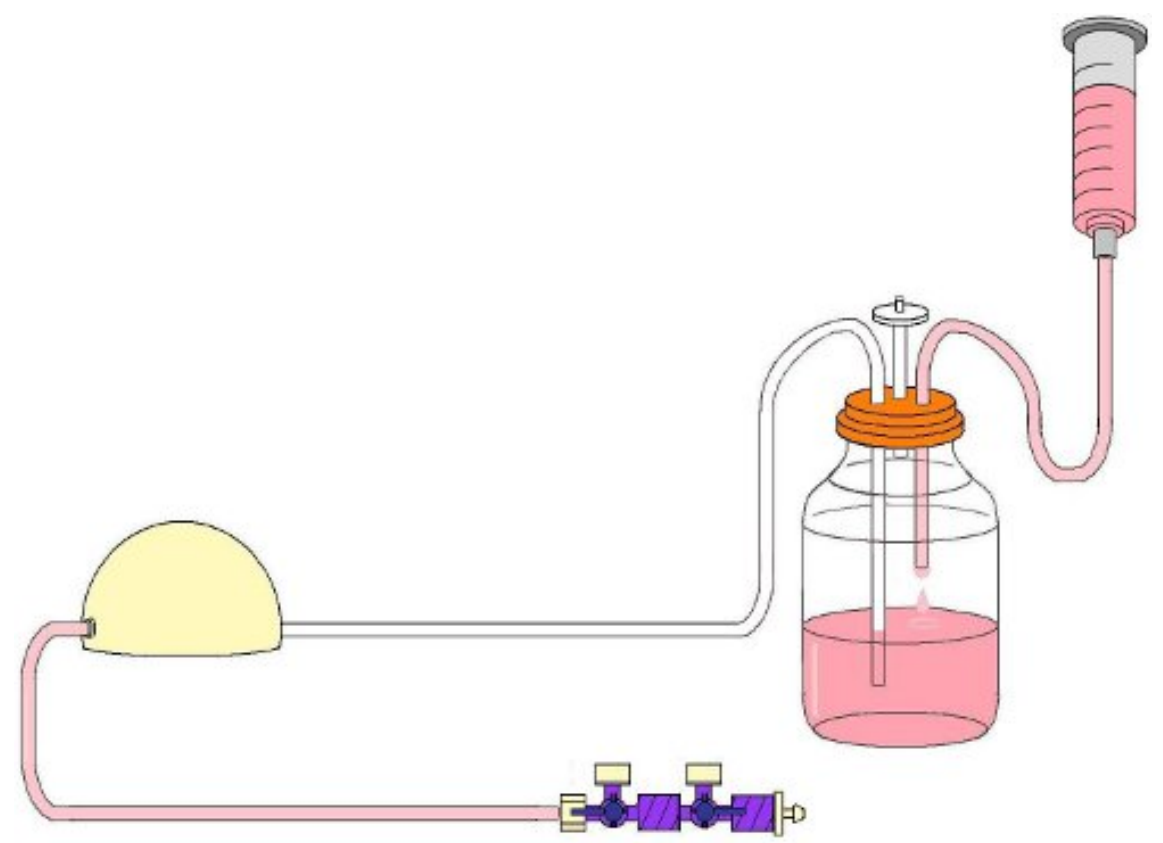

Figure 4. Filling the glass reservoir with $125 \mathrm{ml}$ of EPC medium. 


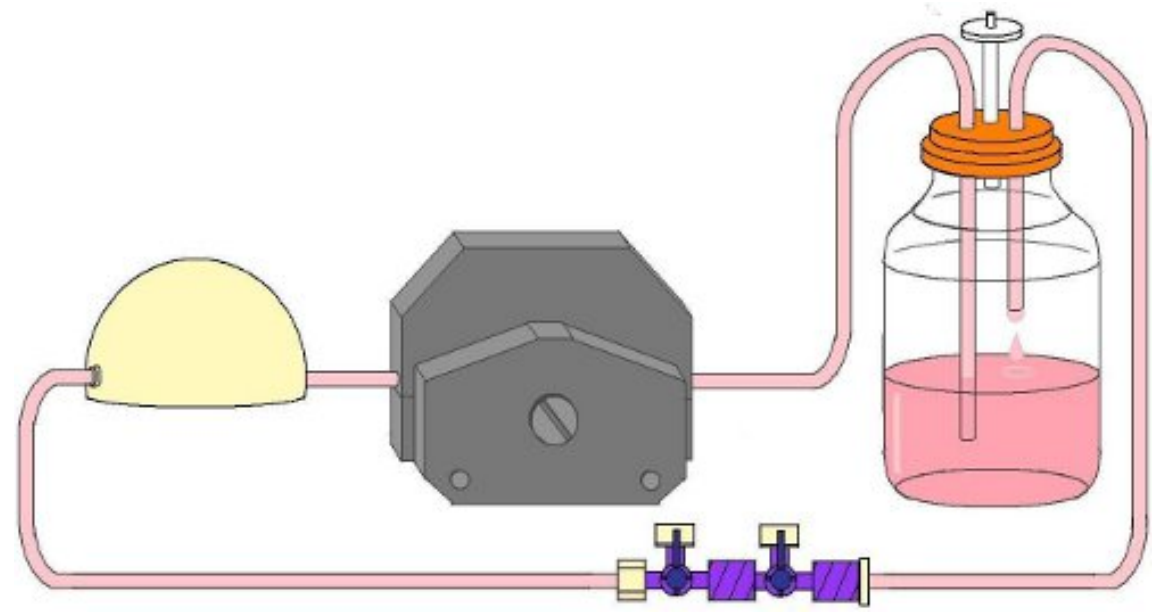

Figure 5. Flow circuit clamped into the flow pump head prior to flow chamber insertion.

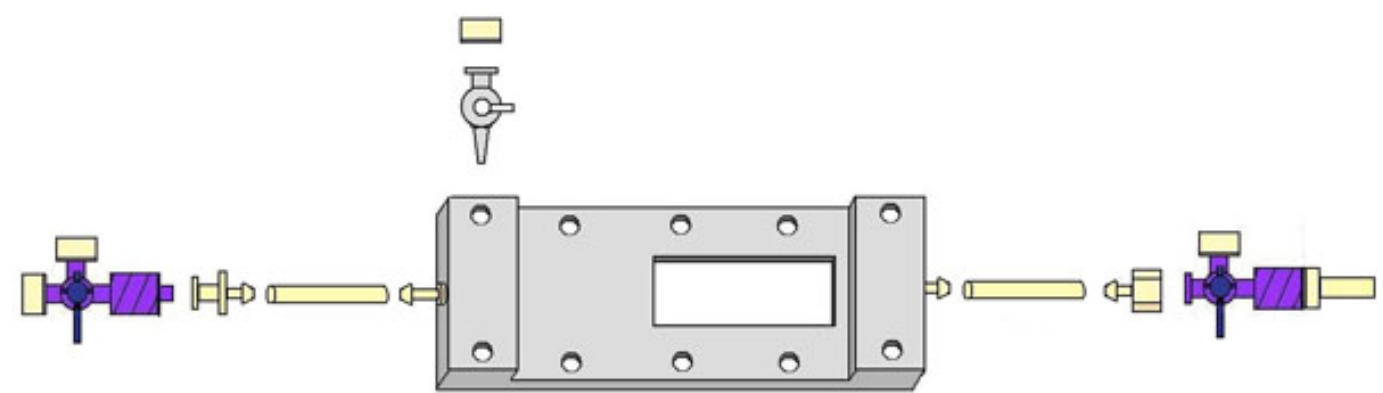

Figure 6. Top chamber plate assembly.

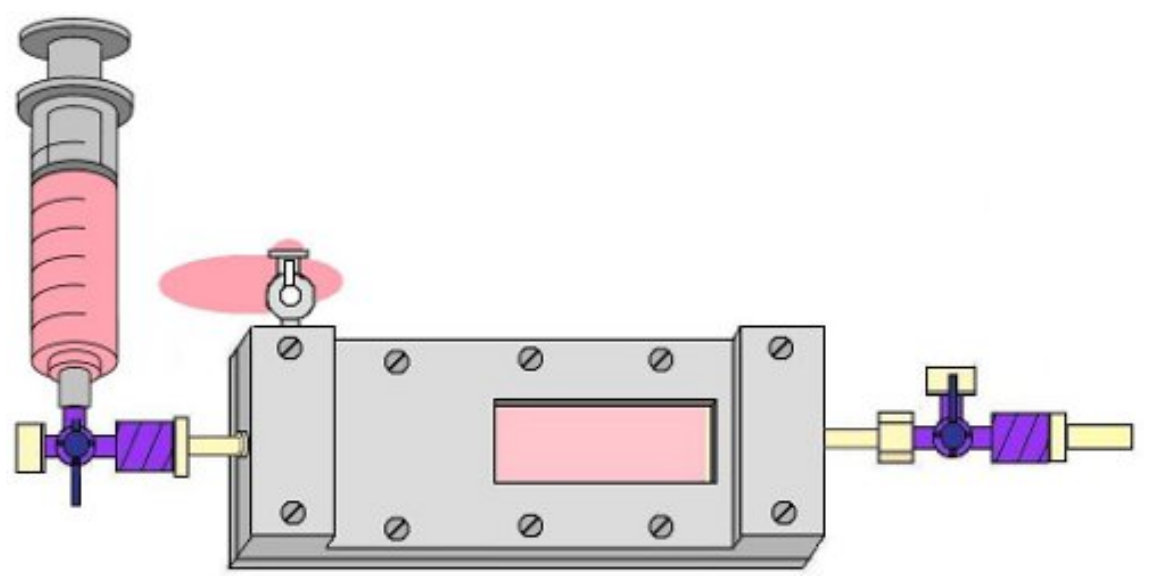

Figure 7. Flushing the bubble trap with EPC medium to remove bubbles from inflow side of the chamber.

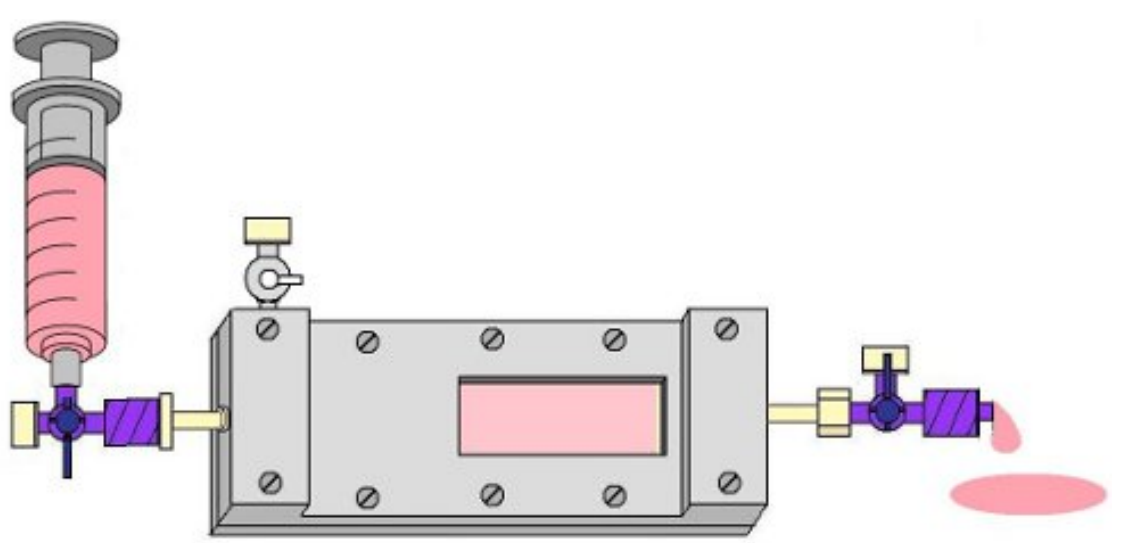


Figure 8. Flushing the chamber with EPC medium to remove bubbles from the slide and outflow side of the chamber.

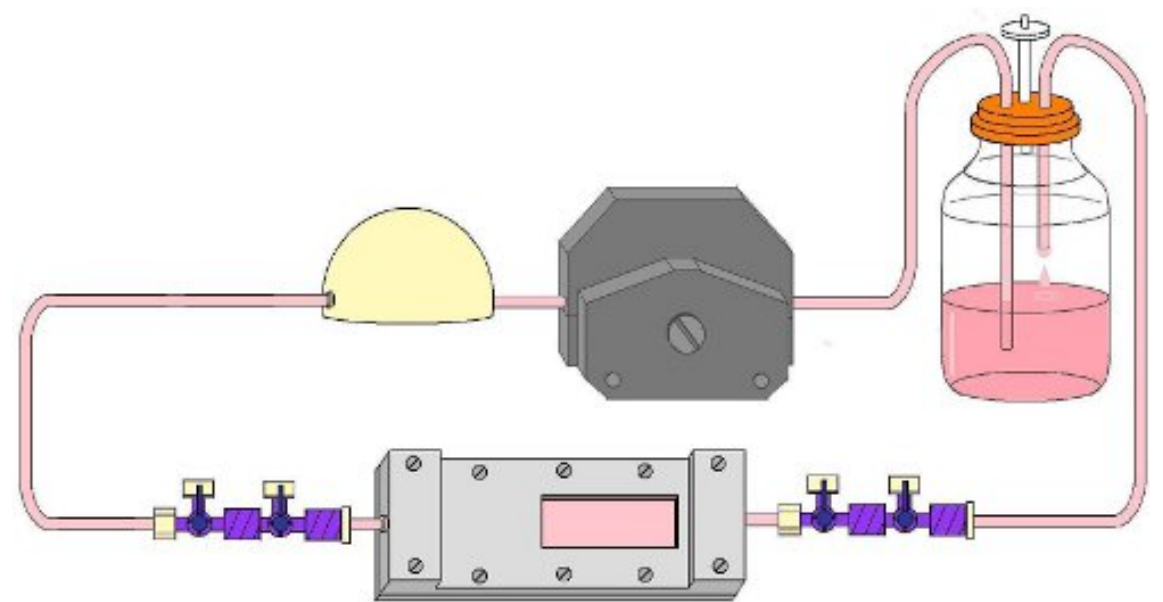

Figure 9. Completely assembled flow circuit with inserted flow chamber during a flow experiment.

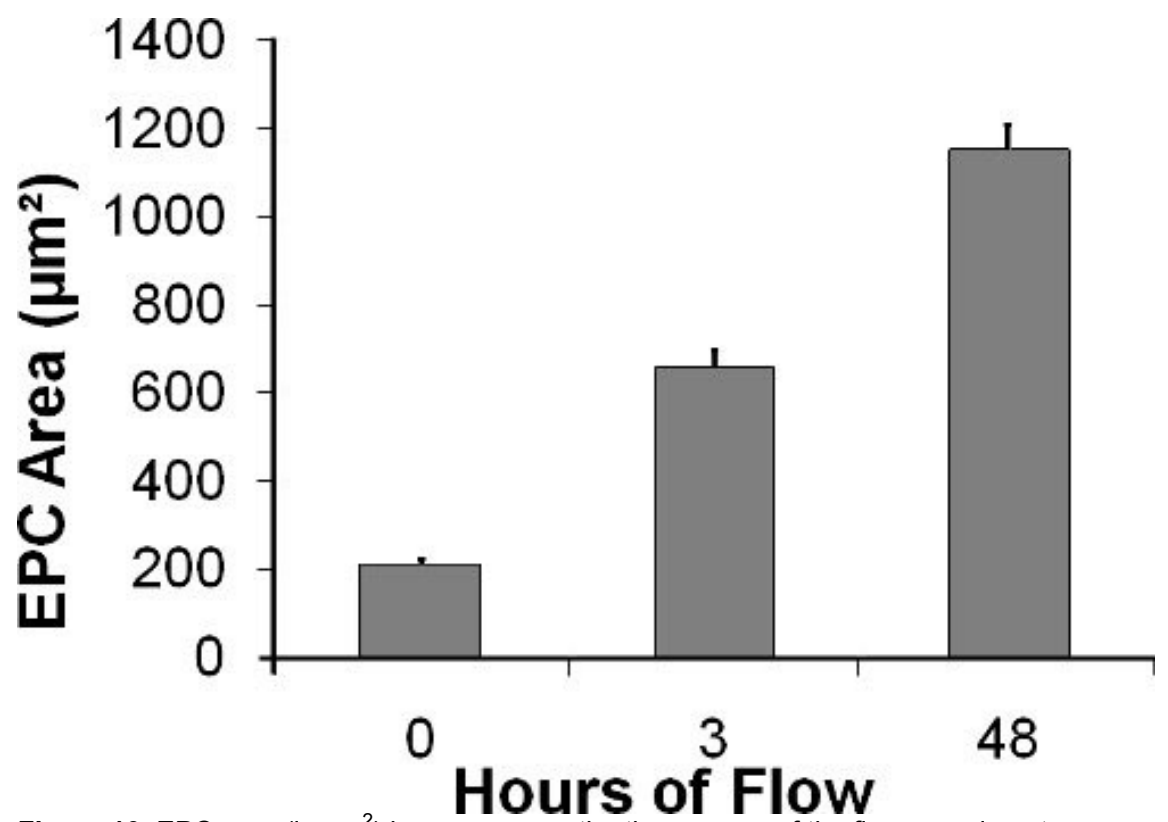

Figure 10. EPC area (in $\mu \mathrm{m}^{2}$ ) increases over the time course of the flow experiment.

A)

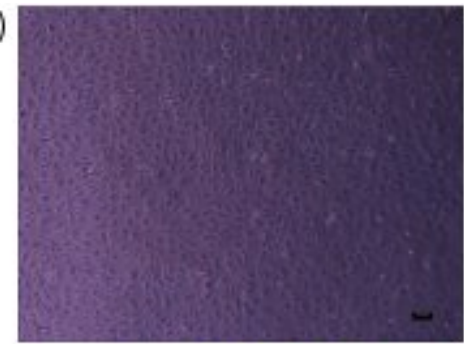

D)

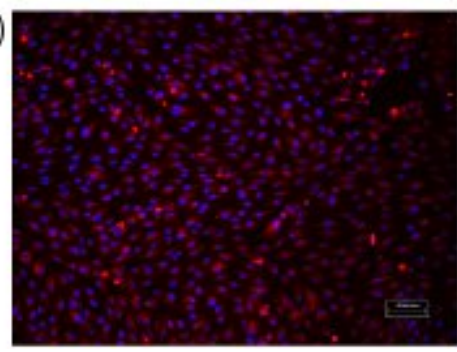

B)

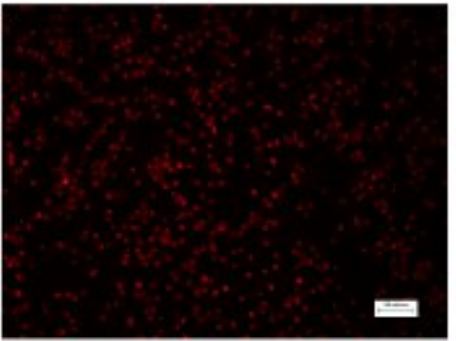

E)

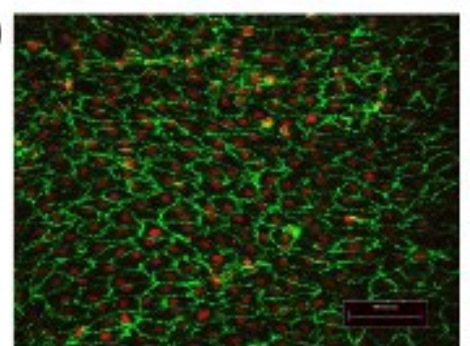

C)

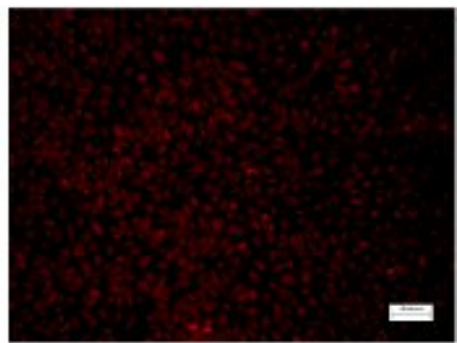


Figure 11. (A) Light microscope image of HUCB EPCs seeded onto a fibronectin coated glass slide $x 6$ hours prior to flow at $100 x$ magnification. (B) HUCB EPCs labeled with CTO and quick-seeded onto a Ti slide $\times 15$ min prior to flow, visualized with fluorescent microscopy at $100 \times$ magnification. (C) The same Ti slide with HUCB EPCs as under (B), after 3 hours of flow at 100 dynes/ $\mathrm{cm}^{2}$ and imaged through the transparent chamber at $100 \times$ magnification. Note the spreading of cells but still random orientation after 3 hours of flow. (D) The same Ti slide, now after 48 hours of flow exposure at $100 \times$ magnification. EPCs are labeled with CTO and cell nuclei are stained with Hoechst dye (blue) after flow. Note the alignment of cells in the direction of flow. (E) Porcine EPCs for comparison on Ti after 48 hours of flow and $15 \mathrm{dynes} / \mathrm{cm}^{2}$ of shear stress exposure. Cell borders were stained with anti-PECAM stain (green) and nuclei with Sytox Orange Nucleic Acid stain. Note the alignment of cells into the direction of flow.

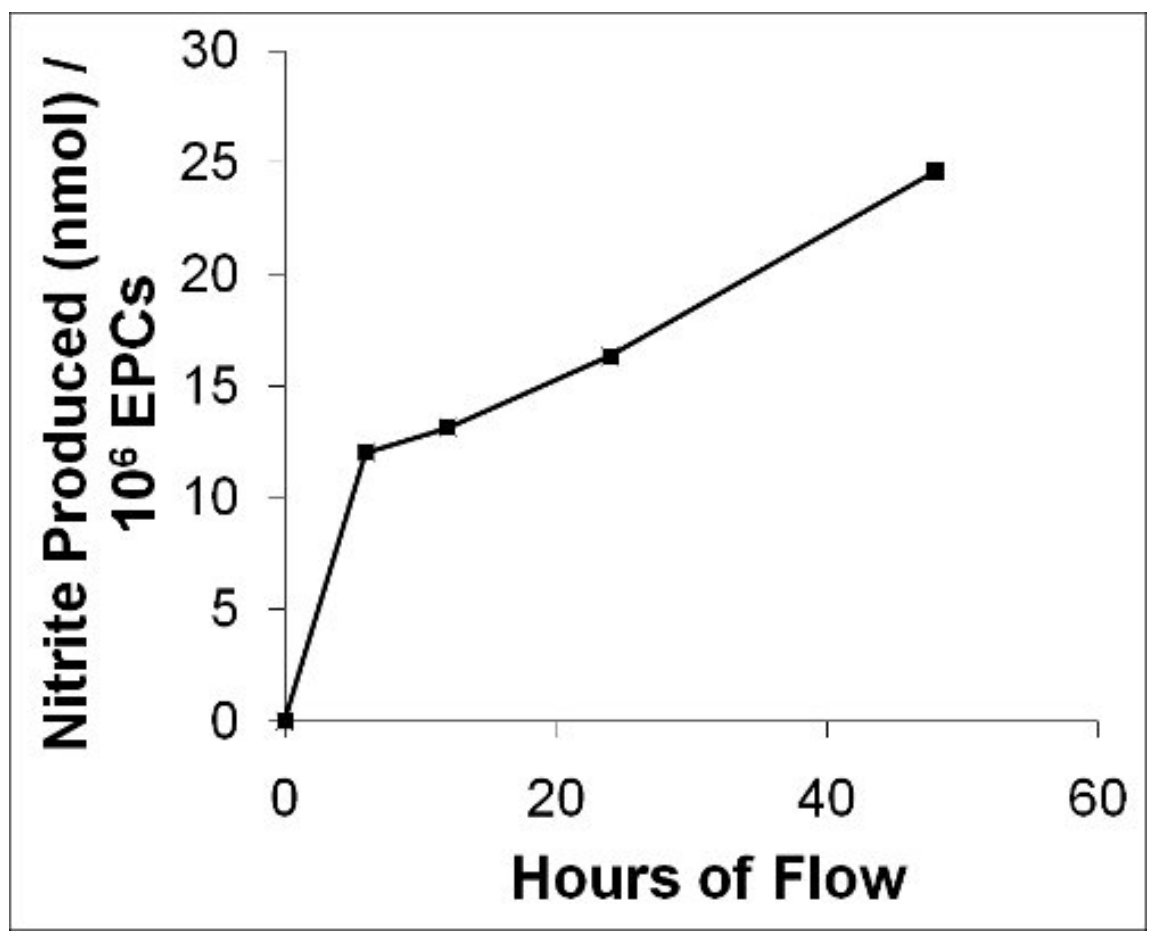

Figure 12. Graph depicts $\mathrm{NO}$ production of porcine EPCs during 48 hours of flow. A primary oxidation product of $\mathrm{NO}$, nitrite $\left(\mathrm{NO}_{2^{-}}\right)$, was measured as a surrogate marker for $\mathrm{NO}$ from medium samples collected at different time points during flow.
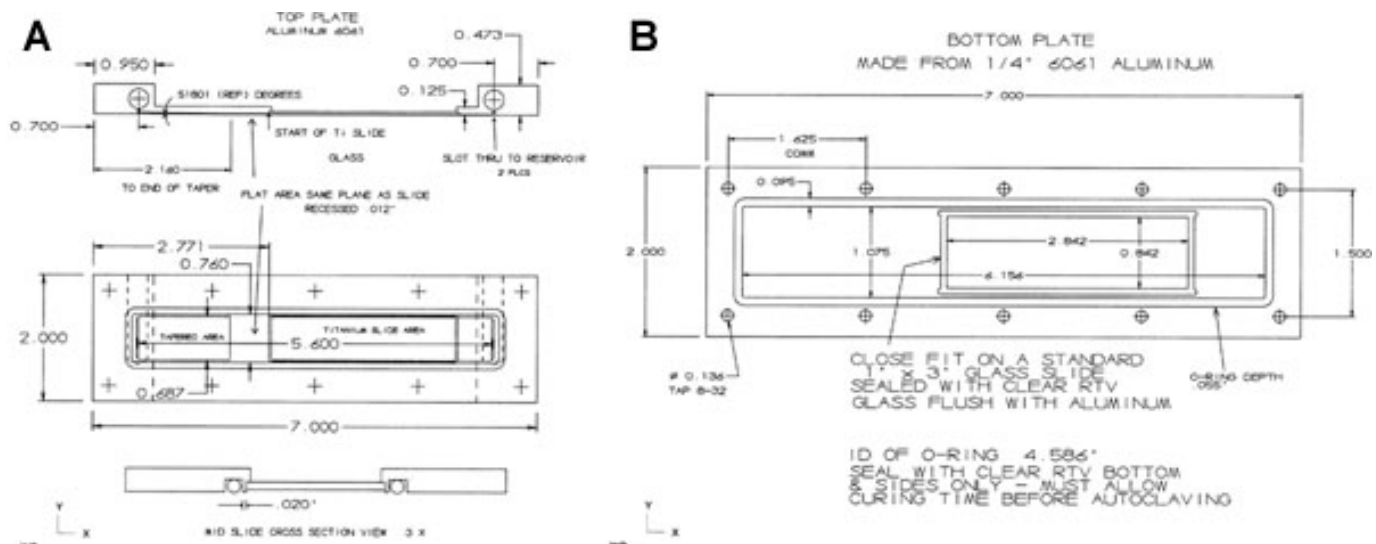

Figure 13. The flow chamber is made from aluminum alloy 6061 rectangular stock, with the top section (A) being $0.5^{\prime \prime} \times 2$ " $\times 7$ " and the bottom section (B) $0.25 " \times 2 " \times 7 "$ in dimension. The top is planed on its underside O-ring contact surface to $0.45^{\prime \prime}$ in order to insure flatness for sealing The top part is recessed in its center portion to 0.125 ", which leaves 0.95 " per end for a 0.3125 " x $1.375^{\prime \prime}$ fluid reservoir. The top section's reservoir is threaded 3/8-24 T.P.I. and 0.25" deep to receive threaded stainless steel plugs. Slots measuring $1 / 16 " \times 0.625 "$ were machined into the underside that penetrate to the reservoir. The inflow side plug has a 10/32" through hole for a polypropylene $1 / 8$ " hose barb to attach to a stopcock. Each unit end has a centrally located threaded 10/32 T.P.I. by 0.25 " deep portion for a polypropylene $1 / 8$ " hose barb in the 0.45 " x 2 " end. The ends use a 0.07 " hole from the bottom of threads through to penetrate the reservoir. The underside of the top section has a tapered area 0.6875 " wide, 0.518 degrees from the center of an LH slot for a distance of $1.460 "$ ". This taper blends to a flat area 0.6875 " wide $\times 0.0118$ " deep and $0.590 "$ from the end of the glass (or other surface, e.g. titanium slide) recess. This flat must be flush with the glass (or other surface, e.g. titanium slide) once the slide is installed. The taper and flat are polished. The surface of the slide is 0.0118 " recessed from the underside surface. The 0.0118 " recess continues to the reservoir slot on the $\mathrm{RH}$ end. An O-ring is recessed entirely around slots and slide leaving $0.020 "$ of original surface between the O-ring groove and slide. The top and bottom units are drilled for ten holes. The top section has clearance holes for $8 / 32$ T.P.I. countersunk flat head screws. The bottom section has holes placed matching the top holes and are threaded 8/32 T.P.I.. The bottom unit has a clear glass slide window recessed flush with its surface located over the cell surface glass slide (or titanium slide). The unit has an O- 
ring groove which encompasses slots in the top unit with width to leave 0.04 " of original surface between the bottom slide and the inner O-ring groove. The O-rings are red silicone AS568A, Dash Number 044 for the top section and 046 for the bottom section. Please click here to see a larger version of figure 13.

\section{Discussion}

Our flow circuit and flow chamber allow us to subject adherent cells, e.g. EPCs, to defined fluid shear stresses. Since the chamber top and bottom are transparent, cell adhesion and morphology can be evaluated either in real-time, through the chamber itself, or after a flow experiment and disassembly of the flow chamber. At that point, cells can be harvested under sterile conditions and either re-plated, or used to collect their DNA or RNA, etc., for further analysis.

To achieve laminar flow, the design of the chamber must be such that several conditions are met.

First, the flow must be laminar, which can be verified by calculating its Reynolds number $(\boldsymbol{R e})$, which is the ratio of inertial forces to viscous forces. (If viscous forces predominate, $\boldsymbol{R e}$ is small and the flow is laminar or 'fully developed' - usually for $\boldsymbol{R e}<2300$. If inertial forces predominate, the flow becomes more and more random until it is turbulent, as is the case for $\boldsymbol{R e}>4000$.) We can calculate $\boldsymbol{R e}$ according to equation $3^{8}$,

$\boldsymbol{R e}=\frac{\rho \cdot Q \cdot D_{h}}{\mu \cdot \boldsymbol{w} \cdot \boldsymbol{h}}$

Where $\boldsymbol{\rho}$ is the fluid density, $\boldsymbol{Q}$ is the flow rate, $\boldsymbol{\mu}$ is the viscosity, $\boldsymbol{w}$ and $\boldsymbol{h}$ are the width and height of the chamber, respectively, and $\boldsymbol{D}_{\boldsymbol{h}}$ is the hydraulic diameter, defined according to equation $4^{8}$,

$$
D_{h}=\frac{4 \cdot \text { Cross }- \text { Sectional Area }}{\text { Wetted Perimeter }}=\frac{4 w \cdot h}{2 \cdot(w+h)}
$$

The Reynolds number of our three flow chambers, with heights ranging from 166 - $267 \mu \mathrm{m}$, range from 13.9 - 34.6 at flow rates calculated to obtain a shear stress of 15 dynes $/ \mathrm{cm}^{2}$. At flow rates calculated for a shear stress of 100 dynes $/ \mathrm{cm}^{2}$, the Reynolds number of the chambers ranged from 90.4 - 234. All of these Reynolds numbers are much lower than 2300 and meet the criterion for laminar flow.

Second, for the velocity field and shear stress to be independent of the distance along the flow channel (i.e. fully developed), the distance from the fluid inlet to slide must be longer than the entrance length, $L_{\mathrm{e}}$. This can be satisfied by calculating the entrance length, according to equation $5^{9}$.

$$
L_{e}=0.04 h R_{e}
$$

For the values listed above, the entrance length ranges from 0.01 to $0.25 \mathrm{~cm}$.

Third, in order to ensure that the velocity and shear stress in the lateral direction do not vary significantly from the value for one-dimensional channel flow $(\Delta \boldsymbol{P h} / \mathbf{2} L)$, the ratio $\boldsymbol{h} / \boldsymbol{w}$ must be much less than 1 . For the average wall shear stress under two-dimensional flow conditions to be $95 \%$ of the wall shear stress under one-dimensional flow, $\mathrm{h} / \mathrm{w}$ must be equal to 0.10 , and for the wall shear stress under two-dimensional flow conditions to be $97.5 \%$ of the wall shear stress under one-dimensional flow, $\mathrm{h} / \mathrm{w}$ must be equal to 0.05 . With the dimensions of our designed flow chamber $1.7 \mathrm{~cm}$ in width and $166-267 \mu \mathrm{m}$ in height, these criteria are satisfied.

The pressure will vary only in the direction of flow if there are no lateral pressure gradients at the entrance. This can be assessed using dyes or particles in the flow path. Further, for steady flow experiments, a pulse dampener is inserted in the flow circuit. The pulse dampener takes out most of the pulsatility caused by the roller pump in the circuit, and allows us to approximate the assumption of steady flow. Of note, the pulse dampener utilized should be compatible with the pump and tubing used in the circuit, so that it can effectively eliminate pulsations in the output flow for the specific frequencies of the roller pump. In our demonstration the Masterflex L/S pulse dampener achieves laminar flow when used on the discharge line with any Masterflex L/S series pump (0 - 600 RPMs) and I/P 26 tubing. For pulsatile flow, a programmable pump can be used to generate various waveforms.

For pulsatile flow, a programmable pump can be used to generate various waveforms.

Furthermore, the circuit is designed such that samples of perfusate can easily be collected at different time points without risking contamination of the cells or flow medium. In our example, the concentration of $\mathrm{NO}_{2}$ - was measured by chemiluminescence with an lonics/Sievers Nitric Oxide Analyzer (NOA 280, Sievers Instruments, Boulder, CO) as previously described ${ }^{10}$. The reductant used for nitrite analysis was potassium iodide in acetic acid $(14.5 \mathrm{M}$ acetic acid and $0.05 \mathrm{M} \mathrm{KI}$ ), which has the reduction potential to convert nitrite to NO but is insufficient to reduce any higher oxides of nitrogen such as nitrate and thus is relatively specific for nitrite. The total amount nitrite produced was calculated as the product of concentration produced and the total volume of the circuit while adjusting for volume lost while taking samples ${ }^{6}$.

\section{The following steps are critical for the successful execution of flow experiments:}

i. It is desirable to avoid bubble formation during the flow set-up, since bubbles have the potential to tear off cells from their surface. This can be avoided by taking care when placing the top part of the flow chamber onto the bottom part, which is best accomplished by keeping both parallel to each other and lowering the top onto the bottom in one motion without readjustments. In doing so, small air bubbles that may be present and/ or floating in the flow channel, will be diverted into the bubble traps on either end of the aluminum housing. 
ii. It is important to ensure that the outflow tubing in the reservoir reaches down to the reservoir's bottom. Otherwise, air may be sucked into the tubing that leads from reservoir to chamber if the perfusate level falls slightly below the tubing end.

iii. The researcher should be familiar with the direction of the pump flow so that the pump does not accidentally run in the opposite direction upon commencement of flow, which would result in air being sucked into the circuit and chamber.

iv. To avoid the formation of foam (due to denatured proteins contained in serum), we advise lowering the tubing that leads from chamber to reservoir to approximately one inch above the perfusate level inside the reservoir. However, keeping it above the flow medium level allows you to verify flow into the reservoir during the experiment.

v. When screwing the chamber parts together, it is important to firmly grasp the housing with one hand while operating the electric screwdriver with your other hand. Note that the motion of the electric screwdriver will be translated into torque which has the potential to 'fling the chamber around' once the screw is tightened.

vi. To avoid any pressure waves from forming in the circuit and lifting cells off their surface, ensure that all stopcocks are open before commencing flow.

vii. Especially for longer term flow studies (> 48 hours) we recommend using the harder and more resilient tubing to be inserted into the pump head to prevent breaking of tubing.

viii. It is possible that tubing 'migrates' inside the pump head due to ill-adjusted pump head teeth. Therefore we suggest paying close attention to how the tubing is secured in the pump head and marking each end of the tubing with a marking pen such that you can easily notice if the tubing is 'pulled in' or dislodged during the experiment.

ix. Always carefully check every single connector of the circuit and chamber prior to starting the perfusion in order to prevent leakage of perfusate during an experiment due to a faulty connection. This is especially important for the inflow and outflow connectors of pulse dampeners!

$x$. Remember to limit light exposure if you use fluorescent labels.

A possible limitation of our flow chamber is that the height is fixed by the height of the channel machined into the aluminum. However, this has the advantage of not having to verify and adjust the height of the channel prior to each experiment and therefore simplifies the shear stress calculations by merely adjusting the pump flow to the desired value. Depending on your research goals, it may be desirable to increase the shear stress without increasing pump speed. In this case we recommend increasing the perfusate's viscosity, e.g. adding dextran to the medium ${ }^{11}$.

A possible limitation of the flow circuit is the large volume of medium used, which can be problematic when attempting to quantify very small concentrations of cell metabolites. Though not shown here, it is possible to substantially reduce the circuit volume by using a smaller reservoir and pulse dampener and decrease tubing length and diameter.

Additionally, there are several other commercially available systems that can be used to apply fluid shear stress to cells in culture. Microfluidicbased systems, e.g. the BioFlux system from Fluxion, enable simultaneous analyses of cells in different microfluidic flow channels loaded with solution into well plates acting as input and output reservoirs for these channels ${ }^{12,13,14}$. However, these and other microfluidic systems are not compatible with standard microscope slides and do not allow for recovery of a sufficiently large number of cells for further experiments, such as RT-PCR or Western Blot. Further, they are less user-friendly, cost a minimum of $\$ 40,000$ and may reach a total of more than $\$ 100,000$, depending on accessory equipment.

Two macrofluidic systems available from the Flexcell International Corporation, the Flexcell Streamer and the FlexFlow systems, have been successfully used to study endothelial cells ${ }^{15,16,17}$, human annulus cells ${ }^{18}$ and fibroblasts ${ }^{19}$ under fluid flow conditions. A third system, available through GlycoTech, has been utilized to study tumor cell adhesion ${ }^{20}$ and leukocyte adhesion ${ }^{21}$ to endothelial monolayers.

The Streamer system allows several slides to be run under the same shear stress conditions at once, but lacks a viewing window and - unlike our design - does not allow for real-time visualization of cells under flow.

The FlexFlow system has a viewing window, but requires an upright microscope, which might not be the standard microscope used in most laboratories. Further, the FlexFlow system requires a cell-coated cover slip to be inverted when placed into the flow chamber. This precludes visualization of fluorescent cells on an opaque surface, such as titanium-coated glass, which we demonstrate in our study. Lastly, the specialized cover slips need to be purchased specifically for the FlexFlow system, which is in the multi-thousand-dollar price range, similar to the Flexcell Streamer system.

GlycoTech offers circular and rectangular parallel-plate flow chambers, which are significantly less expensive, but manufactured from cast acrylic that cannot conveniently be stem autoclaved like our chamber. Of note, other flow chambers that have been described to be autoclavable appear impractical because they require special microscopic lenses ${ }^{22,23}$. The GlycoTech system utilizes silicon rubber gaskets interposed between top and bottom plates, which will change in thickness with repeated use and therefore change chamber height over time (the manufacturer recommends purchasing new ones after every ten uses). Our aluminum chamber with built-in O-rings allows for complete opposition of top and bottom plates and ensures constant chamber height between experiments. Lastly, vacuum pumps are necessary to achieve a leak-proof seal in many flow chamber designs, including the GlycoTech chambers, which are not necessary in our design.

Whereas not shown here, the flow chamber can be kept under a microscope during the entire flow experiment for real-time imaging of cell adhesion and/ or behavior. If this is desired, we recommend using heat lamps or a heated pad under the chamber to maintain the perfusate temperature at $37^{\circ} \mathrm{C}$. Further, the roller pump can be replaced with a syringe pump, if no 'recirculation' of either cells or metabolites or investigational drugs or agents is desired ${ }^{24}$.

It is also possible to flow differently labeled cells over adherent cells, e.g. fluorescent platelets over a layer of confluent EPCs (using the platelet assay described by Achneck et al. ${ }^{6,25}$ ) to evaluate cell-to-cell interaction under fluid shear stress. Our flow chamber combines valuable features of other available flow chambers, such as a perfusate sampling port and a viewing window and has the important advantage of compatibility with either an inverted or upright microscope. It is fully autoclavable and allows for repeated experiments at constant chamber height and without the need of vacuum pumps to achieve a leakproof seal. 


\section{Disclosures}

Production and Free Access of this video-article is sponsored by Cole-Parmer Instrument Co.

\section{Acknowledgements}

The authors would like to thank Joe Owen in the Biomedical Instrument and Machine Shop for his tireless efforts in machining and assembling the flow chamber parts and Matt Maudsley from Leica Microsystems for assisting in techniques to image cells through flow chambers. We are indebted to Kevin Collins from Duke Perfusion Services and Dr. Steve Wallace in the Department of Biomedical Engineering for helpful suggestions on flow circuit design. We would also like to thank the National Science Foundation Graduate Research Fellowship Program for supporting Alexandra Jantzen and the NIH for their support through Grant "Autologous EPC lining to improve biocompatibility of circulatory assist devices" RC1HL099863-01.

\section{References}

1. Bhat, V.D., Truskey, G.A., \& Reichert, W.M. Fibronectin and avidin-biotin as a heterogeneous ligand system for enhanced endothelial cell adhesion. J. Biomed. Mater. Res. 41, 377-385, doi:10.1002/(SICI)1097-4636(19980905)41:3<377::AID-JBM6>3.0.CO;2-9 [pii] (1998).

2. Broxmeyer, H.E., et al. Cord blood stem and progenitor cells. Methods Enzymol. 419, 439-473, doi:S0076-6879(06)19018-7 [pii] 10.1016/ S0076-6879(06)19018-7 (2006).

3. Achneck, H.E., et al. In American Heart Association Scientific Sessions, Abstract Oral Sessions, Medical Aspects End Stage Heart Failure: Transplantation and Device Therapies (2010).

4. Brown, M.A., Wallace, C.S., Angelos, M., \& Truskey, G.A. Characterization of umbilical cord blood-derived late outgrowth endothelial progenitor cells exposed to laminar shear stress. Tissue. Eng. Part. A. 15, 3575-3587, doi:10.1089/ten.TEA.2008.0444 (2009).

5. Achneck, H.E., et al. Regenerating titanium ventricular assist device surfaces after gold/palladium coating for scanning electron microscopy. Microsc. Res. Tech. 73, 71-76, doi:10.1002/jemt.20757 (2010).

6. Achneck, H.E., et al. The biocompatibility of titanium cardiovascular devices seeded with autologous blood-derived endothelial progenitor cells: EPC-seeded antithrombotic Ti Implants. Biomaterials. 32, 10-18, doi:S0142-9612(10)01111-7 [pii] 10.1016/j.biomaterials.2010.08.073 (2011).

7. Rinker, K.D., Prabhakar, V., \& Truskey, G.A. Effect of contact time and force on monocyte adhesion to vascular endothelium. Biophys. J. 80, 1722-1732, doi:10.1016/S0006-3495(01)76143-7 (2001).

8. Truskey, G.A., Yuan, F., \& Katz, D.F. In Transport Phenomena in Biological Systems., Ch. 2, Horton, M.J., ed., Pearson Education, (2004).

9. Truskey, G.A., Yuan, F., \& Katz, D.F. In Transport Phenomena in Biological Systems., Ch. 2, Horton, M.J., ed., Pearson Education, (2009).

10. Allen, J.D., et al. Plasma nitrite response and arterial reactivity differentiate vascular health and performance. Nitric Oxide. 20, 231-237, doi:S1089-8603(09)00011-1 [pii] 10.1016/j.niox.2009.01.002 (2009).

11. Xiao, Y. \& Truskey, G.A. Effect of receptor-ligand affinity on the strength of endothelial cell adhesion. Biophys. J. 71, 2869-2884, doi:10.1016/ S0006-3495(96)79484-5 (1996).

12. Conant, C.G., Schwartz, M.A., Nevill, T., \& lonescu-Zanetti, C. Platelet Adhesion and Aggregation Under Flow using Microfluidic Flow Cells J. Vis. Exp. (32), e1644, DOI: 10.3791/1644 (2009).

13. Conant, C.G., Schwartz, M.A., \& lonescu-Zanetti, C. Well plate-coupled microfluidic devices designed for facile image-based cell adhesion and transmigration assays. J. Biomol. Screen. 15, 102-106, doi:10.1177/1087057109353789 (2010).

14. Conant, C.G., et al. Using well-plate microfluidic devices to conduct shear-based thrombosis assays. J. Lab. Autom. 16, 148-152, doi:10.1016/j.jala.2010.10.005 (2011).

15. Metaxa, E., et al. Nitric oxide-dependent stimulation of endothelial cell proliferation by sustained high flow. Am. J. Physiol. Heart. Circ. Physiol. 295, H736-742, doi:10.1152/ajpheart.01156.2007 (2008).

16. Radel, C., Carlile-Klusacek, M., \& Rizzo, V. Participation of caveolae in beta1 integrin-mediated mechanotransduction. Biochem. Biophys. Res. Commun. 358, 626-631, doi:10.1016/j.bbrc.2007.04.179 (2007).

17. Wang, X.L., Fu, A., Spiro, C., \& Lee, H.C. Proteomic Analysis of Vascular Endothelial Cells-Effects of Laminar Shear Stress and High Glucose. J. Proteomics. Bioinform. 2, 445, doi:10.4172/jpb.1000104 (2009).

18. Elfervig, M.K., Minchew, J.T., Francke, E., Tsuzaki, M., \& Banes, A.J. IL-1beta sensitizes intervertebral disc annulus cells to fluid-induced shear stress. J. Cell. Biochem. 82, 290-298 (2001).

19. Archambault, J.M., Elfervig-Wall, M.K., Tsuzaki, M., Herzog, W., \& Banes, A.J. Rabbit tendon cells produce MMP-3 in response to fluid flow without significant calcium transients. J. Biomech. 35, 303-309 (2002)

20. Patton, J.T., Menter, D.G., Benson, D.M., Nicolson, G.L., \& Mclntire, L.V. Computerized analysis of tumor cells flowing in a parallel plate chamber to determine their adhesion stabilization lag time. Cell. Motil. Cytoskeleton. 26, 88-98, doi:10.1002/cm.970260109 (1993).

21. Wiese, G., Barthel, S.R., \& Dimitroff, C.J. Analysis of Physiologic E-Selectin-Mediated Leukocyte Rolling on Microvascular Endothelium. J. Vis. Exp. (24), e1009, DOI: 10.3791/1009 (2009).

22. Kaper, H.J., Busscher, H.J., \& Norde, W. Characterization of poly(ethylene oxide) brushes on glass surfaces and adhesion of Staphylococcus epidermidis. J. Biomater. Sci. Polym. Ed. 14, 313-324 (2003).

23. Bakker, D.P., van der Plaats, A., Verkerke, G.J., Busscher, H.J., \& van der Mei, H.C. Comparison of velocity profiles for different flow chamber designs used in studies of microbial adhesion to surfaces. Appl. Environ. Microbiol. 69, 6280-6287 (2003).

24. Angelos, M.G., et al. Dynamic adhesion of umbilical cord blood endothelial progenitor cells under laminar shear stress. Biophys. J. 99 , 3545-3554, doi:S0006-3495(10)01252-X [pii] 10.1016/j.bpj.2010.10.004 (2010).

25. Baker, G.R., Sullam, P.M., \& Levin, J. A simple, fluorescent method to internally label platelets suitable for physiological measurements. Am J. Hematol. 56, 17-25, doi:10.1002/(SICI)1096-8652(199709)56:1<17::AID-AJH4>3.0.CO;2-5 [pii] (1997). 